\title{
Prospects and Applications of Hydrogel Technology in Agriculture
}

\author{
T.M. Neethu, P.K. Dubey ${ }^{*}$ and A.R. Kaswala \\ Department of Soil Science and Agricultural Chemistry, Navsari Agriculture University, \\ Navsari, Gujarat - 396450, India \\ *Corresponding author
}

\begin{abstract}
A B S T R A C T
Hydrogel is basically a water absorbing polymer, which are classified as cross-linked, absorb aqueous solutions through hydrogen bonding with water molecules. Agricultural hydrogels are referred to as water retention granules because they swell to many times

\section{Keywords}

Hydrgel, SAP, Polymers

\section{Article Info}

Accepted:

22 April 2018

Available Online:

10 May 2018 their original size when they come in contact with water. It has been widely proposed over the last 40 years for agricultural use with the aim to ameliorate water availability for plants, by increasing water holding properties of growing media (soils or soilless substrates). Most of the area of India is located in arid and semiarid Regions, more efficient use of water is essential in the field of agriculture. Implementing proper management practices in agriculture to maintain soil moisture and increase water holding capacity is considered as one of the ways to save water. Super absorbent polymers (SAPs) hydrogel can swell to absorb huge volume of water or aqueous solution. This property has lead to many practical applications of these new materials in particularly in agriculture for improving water retention of soils and the water supply of plants. The relative effectiveness of the hydrogels depends upon chemical properties of the hydrogel, such as molecular weight, and the hydrogel properties tend to have differing effects on various soil properties. This is a short review on applications of hydrogel in agriculture.
\end{abstract}

\section{Introduction}

Agriculture is under abiotic stresses (drought, salinity and temperature) which likely to increase due to land degradation, urbanization and climate change. In India, most of the area is located in arid and semi-arid regions. Irrigation water is becoming scarce and the world is looking for water-efficient agriculture. Increasing food demand and declining water resources are challenges for food security (Kreye et al., 2009). So under such areas, proper management practices should be done inorder to conserve moisture and to increase water holding capacity of the soil. Then also the yield of the crops will be lower as compared with normal conditions. The best possible solution to the above said problem is 'hydrogel'. Hydrophilic gels called hydrogels are cross-linked materials absorbing large quantities of water without dissolving that absorb substantial amounts of aqueous solutions. Softness, smartness and the capacity to store water make hydrogels unique (Shibayama and Tanaka, 1993). Hydrogelforming natural polymers include proteins such as collagen and gelatin, and polysaccharides such as alginate and agarose. 
Synthetic polymers that form hydrogels are traditionally prepared using chemical polymerization methods. In the real sense, hydrogel is a single polymer molecule, that is the network chains in the gel which are connected to each other to form one big molecule on macroscopic scale. The terms gels and hydrogels are used interchangeably. The gel is a state that is neither completely liquid nor completely solid. These half liquidlike and half solid-like properties cause many interesting relaxation behaviors that are not found in either a pure solid or a pure liquid state. Hydrogels may exhibit drastic volume changes in response to specific external stimuli, such as the temperature, solvent quality, pH, electric field etc. (Tanaka, 1978). Agricultural hydrogels are synthetic polymers generally made from petroleum products. They absorb many times their weight in water, and can be distributed into dry regions in order to improve the soil ability to absorb water. Hence, it is known as Super Absorbent Polymer (SAP). Due to their excellent properties, these SAPs were already well established in various applications such as disposable diapers, hygienic napkins, cement, drug delivery systems, sensors, and agriculture. The most essential components of these applications are water absorbency and water retention.

\section{Characteristics of super absorbent polymers}

Taking into account the water imbibing characteristics of SAP materials, the possibilities of its application in the agricultural field has increasingly been investigated to alleviate certain agricultural problems. SAP hydrogels potentially influence soil permeability, density, structure, texture, evaporation, and infiltration rates of water through the soils. Particularly, the hydrogels reduce irrigation frequency and compaction tendency, stop erosion and water runoff, and increase the soil aeration and microbial activity (Rehim et al., 2011). In arid areas, the use of SAP in the sandy soil, to increase its water-holding capacity seems to be one of the most significant means to improve the quality of plants (Bakass et al., 2012). The SAP particles may be taken as "miniature water reservoirs" in soil. Water will be removed from these reservoirs upon the root demand through osmotic pressure difference. The hydrogels also act as a controlled release system by favouring the uptake of some nutrient elements, holding them tightly, and delaying their dissolution. Consequently, the plant can still access some of the fertilizers, resulting in improved growth and performance rates (Liang et al., 2007). SAPs can also be used as retaining materials in the form of seed additives (to aid in germination and seedling establishment), seed coatings, root dips, and for immobilizing plant growth regulator or protecting agents for controlled release (Rehim et al., 2011).

A distinctive instance for the agricultural application of SAP has been recently practiced. Several previous studies showed that these are very useful under limited water conditions to cope with plant water needs (Henderson and Hensley, 1985; Ingram and Yeager, 1987; Wang and Gregg, 1990). Johnson (1984) reported that addition of hydrogel at the rate of $2 \mathrm{~g} / \mathrm{kg}$ improved the water holding capacity of sand from $171 \%$ to $402 \%$. Application of hydrogel decreases the irrigation requirements of several crops by improving water holding capacity resulting in delay and onset of permanent wilting percentages under intense evaporation. An increase in water holding capacity due to hydrogel amendment significantly reduced the irrigation requirement of many plants (Taylor and Halfacre, 1986). The salient features of hydrogel in general is given below,

Less affected by salts 
Exhibits maximum absorbency @ temperatures $\left(40-50^{\circ} \mathrm{C}\right)$ characteristic of semi-arid and arid soils

Absorbs water 400 times its dry weight and gradually releases the same

Stable in soil for a minimum period of one year

Low rates of soil application $-1-2 \mathrm{~kg} /$ ha for nursery horticultural crops; $2.5-5 \mathrm{~kg} / \mathrm{ha}$ for field crops

Reduces leaching of herbicides and fertilizers

Helps plants withstand prolonged moisture stress

Improves physical properties of soils and soil less media

Improves seed germination and seedling emergence rate

Improves root growth and density

Reduces nursery establishment period

Reduces irrigation and fertigation requirements of crops

Promotes early and dense flowering and fruiting/ tillering

Delays onset of permanent wilting point

Extensive root growth resulting in increased water and nutrient use efficiency

Desirable characteristics of hydrogel for applications in agriculture

High absorption capacity in saline and hard water conditions
Optimized absorbency under load (AUL)

Lowest soluble content and residual monomer

Low price

High durability and stability in the swelling environment and during storage

Gradual biodegradability without formation of toxic species

The $\mathrm{pH}-$ neutrality after swelling in water

Photo stability

Re- wetting capability

Physical-chemical characteristics of hydrogels

The most important properties of hydrogels for their use as soil moisture-absorbers, refer to swelling which depends on the structure of the hydrogel and on the external conditions.

Due to the nature of polyelectrolytes the structure of most hydrogels can be characterized by a thermodynamic interaction parameter of the polymer with water, density of mesh points, proportion of ionic groups and their degree of dissociation.

The value of the equilibrium degree swelling of hydrogel is defined by the zero swelling pressure of hydrogel, which in turn consists of osmotic forces, elasticity of mesh and availability of the related ions (Chen et al., 2004). The process of swelling experimentally investigated by the methods from optical measurement of geometric dimensions, visualized correct form samples (cylinders, spheres) automatic registration volume of liquid that remains after its absorption by the sample (Geesing and Schmidhalter, 2004). 


\section{Hydrogel agriculture technology}

Hydrogel agriculture technology involves gel forming polymers that are insoluble water absorbing polymers designed exclusively for agricultural use by the late 1980's. They were developed to improve physical properties of soil to:

Increase water holding capacity

Increase water use efficiency

Enhance soil permeability and infiltration rate

Reduce irrigation frequency

Reduce compaction tendency

Stop soil erosion, farm run-off \& surface leaching

Increase plant performance, particularly in structure-less soils stressed with drought condition

Hydrogels as they are commonly called as cross-linked three-dimensional networked water absorbent polymers. Three main types of Hydrogels have so far been found appropriate for agricultural use:

Starch-graft copolymers

Cross-linked Polyacrylates

Cross-linked Polyacrylamides and Acrylamide-acrylate copolymers

Potassium Polyacrylate is the principle material used in SAP industry and marketed as hydrogel for agricultural use because of its longer retention and high efficiency in soil with nil toxicity issues. They are prepared by polymerizing Acrylic acid with a cross linker. Cross-linked polymers can hold water 400 times their own weight and release $95 \%$ of that to growing plants (Johnson, 1984*; Bowman and Evans, 1991). Use of Hydrogel leads to increased water use efficiency by preventing leaching and increasing frequency for irrigation.

During summer months particularly in semiarid regions, lack of soil moisture can cause plant stress. Moisture released by hydrogel close to root area helps reduce stress and increase growth and plant performance. Hydrogels can reduce fertilizer leaching and reduce application of pesticides.

\section{Water absorption with hydrogel}

Hydrogel works as water reservoirs round the root mass zones of the plant. In presence of water, it expands to around 200-800 times the original volume. There is ample possibility to trap irrigation and rainwater that can then be collected, stored and gradually released for crop requirements over prolonged durations. Hydrogel mixed with soil increase soil permeability and improve germination rates.

It is compatible with a wide range and type of soils and thus has in general a tendency to increase plant performance and yield. Rainwater retention, soil erosion by storm water run-offs, especially in sloped terrains can be greatly averted. There has been proof of decrease in fruit and vegetable loss due to insect by around 10-30\%

\section{Agriculture specific applications of Hydrogel}

\section{Conservation in agricultural lands}

Addition of hydrogel polymer can increase water retention capacity of soil by $50-70 \%$ with proper amendment with various dosages of soil to hydrogel ratio. Consecutively soil bulk density can reduce by $8-10 \%$. 
Table.1 Application rate of hydrogel in soil

\begin{tabular}{|c|c|}
\hline Type of Soil & Suggested dosage of Hydrogel \\
\hline Arid \& Semi-arid Regions & 4-6 g/kg soil \\
\hline $\begin{array}{l}\text { For all level of water stress treatment and } \\
\text { improved irrigation period }\end{array}$ & $2.25-3 \mathrm{~g} / \mathrm{kg}$ soil \\
\hline $\begin{array}{l}\text { To delay permanent wilting point in sandy } \\
\text { soils }\end{array}$ & $\begin{array}{l}0.2-0.4 \mathrm{~g} / \mathrm{kg} \text { OR } 0.8 \% \text { of soil whichever is } \\
\text { more }\end{array}$ \\
\hline $\begin{array}{l}\text { To reduce irrigation water by } \mathbf{5 0 \%} \text { in } \\
\text { loamy soil }\end{array}$ & $2-4 \mathrm{~g} /$ plant pit \\
\hline $\begin{array}{l}\text { To improve relative water content and leaf } \\
\text { water use efficiency }\end{array}$ & $0.5-2.0 \mathrm{~g} / \mathrm{pot}$ \\
\hline To reduce drought stress & $0.2-0.4 \%$ of soil \\
\hline To prohibit drought stress totally & $225-300 \mathrm{~kg} / \mathrm{ha}$ of cultivated area \\
\hline To decrease water stress & $3 \%$ by weight \\
\hline
\end{tabular}

Schematic diagram of Hydrogel

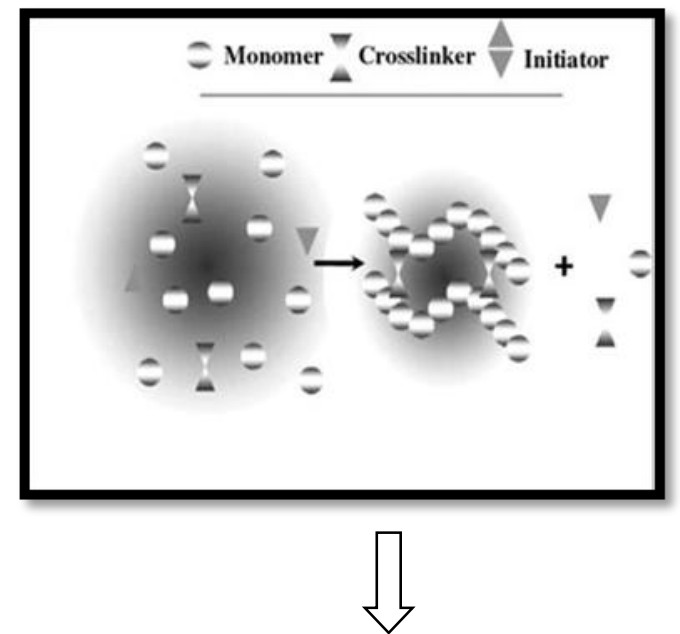

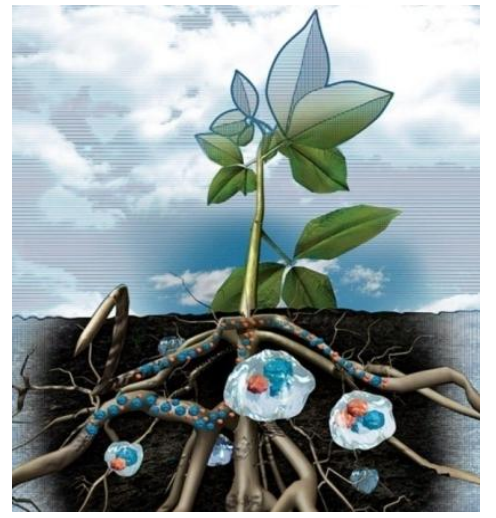

Hydrogel in action at plant roots

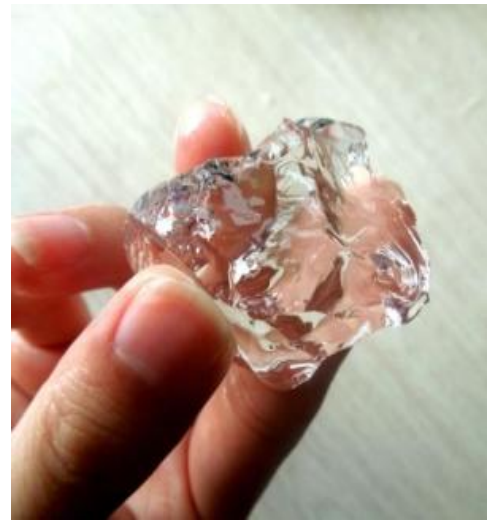

Hydrogel 
There is an upward trend in saturated water volumetric content of soil with increasing dose of hydrogel showing clear signs of increase in agricultural water use efficiency in arid and semi-arid regions. This has positive impact on the net plant yield. Hydrogel directly influences soil permeability, density, structure, texture, evaporation and infiltration rates of water. Irrigation frequency, compaction tendency and run-offs decrease while aeration and microbial activity is promoted.

Water stress due to scarcity of moisture around root zones is often associated with premature leaf shedding, decreasing chlorophyll content, reduced seed yield, less fruit and flower yield per plant. Use of hydrogel can help moderate these impacts caused by deficit irrigation. Being a water retaining agent greatly increase irrigation period of cultivation, enhancing irrigation efficiency particularly in arid and semi-arid belts.

\section{Drought stress reduction}

Drought stress can lead to production of Oxygen radicals that result in increased lipid perioxidation and oxidative stress in the plants. Visible effects include stunned height, decrease in leaf area and foliar matrix damage etc. Hydrogel can reduce drought impact on plants leading to reduced stress and oxygen radical formation. This in turn provides scope for better growth and yield even in unfavorable climatic conditions.

\section{Enhanced fertilizer efficiency}

Irrigation technology has major constraints in the fields of application of fertilizers, herbicides and germicides. Studies suggest the use of synthetic fertilizers can be greatly reduced when hydrogel agriculture is practiced without hindering with crop yield and nutritional value. It would indeed be a more appropriate practice for sustainable agriculture in arid and semi-arid conditions and regions with similar ecological constrains. Moreover, potassium polyacrylate is safe and non-toxic thus prevents pollution of agro ecosystems.

\section{Biodegradability of hydrogel polymer}

Studies have confirmed that hydrogel is sensitive to the action of UV rays, and degrades into oligomers. The polyacrylate becomes much more sensitive to aerobic and anaerobic microbiological degradation and can degrade at rates of $10-15 \%$ per year into water, carbon dioxide and nitrogen compounds. The hydrogel molecules are too voluminous to be absorbed into plant tissue and have zero bioaccumulation potential.

\section{Application rates}

Considering the efficiency of hydrogel in soil conditioning and moisture retention, it can be understood that an optimum mixing ratio is needed to get maximum efficacy of the method. Since the moisture holding capacity is a function of soil characteristics, dosage of hydrogel is also varied and designed based on the type of soil it is used with. A simple dosage chart has been illustrated herein but the ultimate quantity and application can only be determined after testing specific soils to be conditioned.

\section{Influence of hydrogels on water holding capacity of sandy soil}

In general the sandy soil is having less water holding capacity. The hydrogels are best benefited in the sandy soil and as a result best crop yield can be achieved in spite of climatic conditions (Ekebafe et al., 2011). Johnson (1984) mixed sand with different cross-linked polyacrylamides so as to produce a polymer 
concentration range of $0-2 \mathrm{~g} / \mathrm{kg}$. The results indicated that all polymers tested increased the field capacity (FC) of coarse sand to171 and 402\%. Also, Johnson (1984*) showed that the permanent wilting point (PWP) of the control sand was reached between 2-3 days, in comparison with between 6-7 $\mathrm{d}$ for the 1 $\mathrm{g} / \mathrm{kg}$ polymer treated sand and between 9-10 days for the $2 \mathrm{~g} / \mathrm{kg}$ polymer treated sand.

Hydrogel is a boon to dry farming. Most of the area of India is located in Arid and Semiarid Regions, more efficient use of water is essential in the field of agriculture. Implementing proper management practices in agriculture to maintain soil moisture and increase water holding capacity is considered as one of the ways to save water. Super absorbent polymers (SAPs) hydrogel can swell to absorb huge volume of water or aqueous solution. This property has lead to many practical applications of these new materials in particular in agriculture for improving water retention of soils and the water supply of plants.

\section{References}

Abd EI-Rehirn, H. A, Hegazy, E. S. A. and Abd El- Mohdy, H. L. (2004). Radiation synthesis of hydrogels to enhance sandy soils water retention and increase performance, J. Appl. Polym. Sci., 93: 1360-1371.

Bakass, M., Mokhlisse, A. and Lallemant, M. (2002). Absorption and desorption of liquid water by a superabsorbent polymer: Effect of polymer in the drying of the soil and the quality of certain plants, J. Appl. Polym. Sci., 83: 234-243.

Bowman, D. C. and R.Y. Evans (1991). Calcium inhibition of polyacrylamide gel hydration is partially reversible by potassium. HortScience, 26(8): $1063-$ 1065.
Chen, S. L., Zommorodi, M., Fritz, E., Wang, S. and Huttermann, A. (2004). Hydrogel modified uptake of salt ions and Calcium in Populus euphratica under Saline Conditions. Trees Struct Funct., 18: $175-183$.

Ekebafe, L. O., Ogbeifun, D. E. and Okieimen, F. E. (2011). Effect of native cassava starch-poly (sodium acrylateco-acrylamide) hydrogel on the growth performance of maize (Zea may) seedlings. Am J Polymer Sci., 1: 6-11.

Geesing D. and Schmidhalter, U. (2004) Influence of sodium polyacrylate on the water-holding capacity of three different soils and effects on growth of wheat. Soil Use Manag., 20: 207-209.

Henderson, J. C. and Hensley, D. L. (1985). Ammonium and nitrate retention by a hydrophilic gel. HortScience, 20: 667668.

Ingram, D. L. and Yeager, T. H. (1987): Effects of irrigation frequency and a water-absorbing polymer amended on Ligustrum growth and moisture retention by a container medium. Journal of Environmental Horticulture, 5: 19-21.

Johnson, M. S. (1984*). Effect of soluble salts on water absorption by gel-forming soil conditioners. Journal of the Science of Food and Agriculture, 35: 1063-1066.

Johnson, M.S. (1984). The effects of gelforming polyacrylamides on moisture storage in sandy soils. Journal of the Science of Food and Agriculture, 35: 1196-1200.

Kreye C., Bouman, B. A. M., Castaneda, A. R., Lampayan, R. M., Faronilo, J. E., Lactaoen, A. T., Fernandez, L. (2009). Possible causes of yield failure in tropical aerobic rice. Field Crops Research, 111: 197-206.

Liang, M., Zhan, R., Liu, F. and Niu, Z. A. (2007). Preparation of superabsorbent slow release nitrogen fertilizer by 
inverse suspension polymerization, Polym Int., 56: 729-737.

Rehman, A., Ahmad, R. and Safdar, M (2011). Effect of hydrogel on the performance of aerobic rice sown under different techniques, Plant Soil Environ., 57, (7): 321-325.

Shibayama, M. and Tanaka, T. (1993). Phase transition and related phenomena of polymer gels. Advances in Polymer Science, 109: 1-62.

Tanaka, T. (1978). Collapse of gels and the critical end point. Physical Review Letters, 40: 820-823.
Taylor, K. C. and Halfacre, R. G. (1986). Hydrophilic polymer effect on nutrient and water availability to Ligustrum ludicum 'compactum' grown in pinebark medium. HortScience, 18: 603.

Wang, Y. T. and Gregg, L. L. (1990). Hydrophilic polymers - their response to soil amendments and effect on properties of a soil less potting mix. Journal of American Society for Horticultural Science, 115: 943-948.

\section{How to cite this article:}

Neethu, T.M., P.K. Dubey and Kaswala, A.R. 2018. Prospects and Applications of Hydrogel Technology in Agriculture. Int.J.Curr.Microbiol.App.Sci. 7(05): 3155-3162. doi: https://doi.org/10.20546/ijcmas.2018.705.369 